\title{
Integrated bioinformatics analysis of the association between apolipoprotein $E$ expression and patient prognosis in papillary thyroid carcinoma
}

\author{
QUNGUANG JIANG $^{1^{*}}$, WENQIAN FENG ${ }^{2 *}$, CHENGFENG XIONG ${ }^{3}$ and YUNXIA LV $^{3}$ \\ ${ }^{1}$ Department of Gastrointestinal Surgery, First Affiliated Hospital of Nanchang University; \\ Departments of ${ }^{2}$ Operating Room and ${ }^{3}$ Thyroid Surgery, Nanchang University Second Affiliated Hospital, \\ Nanchang, Jiangxi 330006, P.R. China
}

Received May 11, 2019; Accepted October 16, 2019

DOI: $10.3892 / \mathrm{ol} .2020 .11316$

\begin{abstract}
The prognosis of most patients with papillary thyroid carcinoma (PTC) is excellent despite some cases of tumor progression or relapse. The present study was designed to reveal possible prognostic risk indicators for PTC. Differentially expressed genes (DEGs) extracted from 4 Gene Expression Omnibus (GEO) cohorts were subjected to functional enrichment analyses by Gene Ontology (GO) and Kyoto Encyclopedia of Genes and Genome (KEGG) pathway analysis. A dataset from The Cancer Genome Atlas (TCGA) was obtained to filter and validate significant genes using cytoHubba, followed by analysis of their association with clinicopathological characteristics and prognosis. In total, 240 DEGs were identified after data preprocessing. These DEGs were enriched in 'intracellular redox equilibrium', 'release of exosome', 'cell adhesion', 'regulation of extracellular matrix', 'collagen binding' and 'energy metabolism' based on GO analysis which including cellular component, molecular function and biological process. KEGG pathway analysis revealed that the DEGs were enriched in thyroid hormone synthesis, pathways in cancer, focal adhesion, metabolic pathways, apoptosis, PPAR signaling pathway and PI3K/AKT signaling pathway. Using cytoHubba, the following hub genes were identified: Apolipoprotein E (APOE); hemoglobin subunit $\alpha 1$ (HBA1); angiotensin II receptor 1 (AGTR1); collagen I $\alpha 1$ (COL1A1); galectin 3 (LGALS3) and TIMP metallopeptidase inhibitor 1 (TIMP1). The expression of these genes was found to be consistent in TCGA datasets. Kaplan-Meier analysis
\end{abstract}

Correspondence to: Dr Yunxia Lv, Department of Thyroid Surgery, Nanchang University Second Affiliated Hospital, 1 Minde Road, Nanchang, Jiangxi 330006, P.R. China

E-mail: ndefy12389@ncu.edu.cn

*Contributed equally

Key words: Gene Expression Omnibus, The Cancer Genome Atlas, papillary thyroid cancer, prognosis revealed that APOE was significantly associated with overall survival $(\mathrm{P}=0.00067)$ and disease free survival $(\mathrm{P}=0.00220)$. Additionally, low expression of APOE was significantly associated with older age $(\mathrm{P}<0.001)$ and higher TNM stage $(\mathrm{P}<0.001)$ compared with the high expression group. Therefore, APOE may function as a predictive risk indicator for progression as well as prognosis of PTC.

\section{Introduction}

Papillary thyroid carcinoma (PTC) is one of the most prevalent thyroid malignancies; the morbidity and mortality ranks ninth and sixth, respectively, with 567,000 new cases diagnosed and 41,000 cancer-related deaths in 2018 , worldwide (1). In recent years, the widespread application of thyroid ultrasonography and ultrasound-guided fine needle aspiration has improved the diagnosis of PTC in an asymptomatic population (2). Most patients have PTC that is curable, with a 5-year survival rate $>95 \%$. However, a few cases of PTC might occur with invasive features such as tumor recurrence, cervical lymph node involvement and/or distant metastasis, which are associated with poor prognosis $(3,4)$. Therefore, biomarkers that can predict poor outcomes are urgently needed as these would assist clinicians in taking early and appropriate measures for optimal therapeutic benefit.

Current studies have indicated the involvement of various molecular events in the deterioration of PTC $(5,6)$, including BRAF and RAS mutations, rearrangements of RET protooncogene and the excessive activation of the mitogen-activated protein kinase signal transduction pathway (7-10). To date, multiple microRNAs (miRs) and long non-coding RNAs (lncRNAs) have been identified as potential molecular biomarkers, including miR-146b-5p and lncRNA HOTTIP, which have been confirmed to participate in the invasion and metastasis of PTC (11-14). Nevertheless, the majority of these findings are derived from preclinical studies, and large-scale studies of prognostic biomarkers of PTC are lacking.

The development of bioinformatic analysis and the emergence of public database sorting have facilitated the identification of prognostic biomarkers of multiple types of cancer based on large cohorts, including kinesin family 
member 4A for colorectal cancer (15), miR-106a in breast cancer (16) and kirre-like nephrin family adhesion molecule 1 in melanoma (17). In the present study, the Gene Expression Omnibus (GEO) database (18) was used to mine differentially expressed genes (DEGs) between PTC tissues and adjacent normal tissues of PTC. Subsequently, multiple bioinformatics methods, including Gene Ontology (GO) and Kyoto Encyclopedia of Genes and Genome (KEGG) enrichment analysis, construction of a protein-protein interaction (PPI) network and network topological analysis were employed to identify hub genes in DEGs which potentially related to the initiation and progression of PTC. In addition, association of the expression of hub genes with prognosis as well as clinical stage of patients with PTC was validated using The Cancer Genome Atlas (TCGA) database and survival analysis.

\section{Materials and methods}

Microarray data. In total, 4 gene expression datasets of PTC [GSE3678 and GSE3467 (19), GSE60542 (20), and GSE97001 (21)] were downloaded from the GEO database. The GSE3678 dataset contained 7 PTC samples and 7 paired adjacent normal thyroid tissues. The GSE3467 dataset was comprised of 9 PTC samples and 9 paired adjacent normal thyroid tissues. The GSE60542 dataset included 33 PTC samples and 29 paired adjacent normal thyroid tissues. GSE97001 was composed of 4 PTC samples and 4 paired adjacent normal thyroid tissues.

$D E G$ analysis. The $\mathrm{R}$ language limma package (version 3.4.2) (22) (http://www.bioconductor.org/packages/release/bioc/html/limma.html) was used to analyze the DEGs among samples. The adjusted $\mathrm{P}<0.05$ and $\log _{2}$ fold changel $>1$ were taken as the cut-off values. Subsequently, the 4 expression datasets were integrated using the Robust Rank Aggregation (RRA) method (https://cran.r-project. org/web/packages/RankAggreg/RankAggreg.pdf).

$G O$ and KEGG enrichment analyses of DEGs. To assess the potential molecular mechanisms of DEGs in PTC, the Database for Annotation, Visualization and Integrated Discovery (DAVID) online tool (23) was utilized for GO analysis (24) to annotate genes and to define the functions of DEGs into 3 domains: Cellular component, biological process and molecular function. Subsequently, KEGG enrichment analysis was conducted to understand the signaling pathways in which DEGs genes were involved (25).

PPI network construction and topological analysis. The DEG-related PPI network was established using the STRING database (26), followed using visualization by Cytoscape software (version 3.6.1; https://github.com/cytoscape/cytoscape/releases/3.6.1/). Significant genes in the network were subsequently filtered using the Cytoscape plugin cytoHubba (27), which sorts the nodes in the network in accordance with the topological parameters of each node. The hub genes were selected from the intersection of the top 55 DEGs from 12 algorithms by cytoHubba (28).

Validation of DEGs and association with clinicopathological characteristics using a TGCA dataset. Clinical data
Table I. Characteristics of the four GEO datasets.

\begin{tabular}{llcc}
\hline GEO ID & Platform & $\begin{array}{c}\text { Normal } \\
\text { samples, } \mathrm{n}\end{array}$ & $\begin{array}{c}\text { Tumor } \\
\text { samples, } \mathrm{n}\end{array}$ \\
\hline GSE3678 & GPL570 & 7 & 7 \\
GSE3467 & GPL570 & 9 & 9 \\
GSE60542 & GPL570 & 29 & 33 \\
GSE97001 & GPL10332 & 4 & 4 \\
\hline
\end{tabular}

GEO, Gene Expression Omnibus.

and RNA-sequencing data on patients with thyroid cancer were downloaded from TCGA database (29). There were 510 thyroid cancer (THCA) samples and 58 normal samples in the TCGA-THCA cohort. Pathological classifications of non-papillary carcinoma specimens were first excluded, and samples with pathological parameters and follow-up data remained, leaving 493 patients with PTC and 58 normal thyroid samples. Additionally, the expression value of the RNA sequencing data, downloaded as transcripts per million (TPM), was analyzed. The coexpression network of hub genes was identified base on STRING network and CytoScape software was in cBioportal (http://www.cbioportal.org/).

Statistical analysis. R software version 3.4.2 (R Foundation) or GraphPad Prism version 7.0 software (GraphPad, Inc.) were used for statistical analysis. The differential expression of hub genes between normal and PTC tissue were analysed using the Wilcoxon test, and the Kaplan-Meier curves and log-rank test were used for survival analysis of hub genes. $\mathrm{P}<0.05$ was considered to indicate a statistically significant difference. The 'Survminer' package (https://cran.r-project. org/web/packages/survminer/index.html) for R was applied to determine the optimal cut-off value to divide patients into 2 groups based on either high or low gene expression, based on receiver operating characteristic. Pearson's $\chi^{2}$ test or Fisher's exact test were employed to determine the association between DEGs and clinicopathological characteristics of patients with PTC. Moreover, overall survival (OS) and disease-free survival (DFS) were calculated using the R package survival (https://cran.r-project.org/web/packages/survival/index.html). The cut-off value of significant GO terms and KEGG pathway was $\mathrm{P}<0.05$. Univariate Cox proportional hazard models were utilized to explore the prognostic value of the significant DEGs. Subsequently, multivariate Cox regression was used for the identification of independent predictors of PTC.

\section{Results}

Identification of DEGs between PTC and paracancerous tissue A total of 4 datasets were identified in the GEO database: GSE3678, GSE3467, GSE60542 and GSE97001. The characteristics of these studies are presented in Table I. A total of 134 upregulated genes and 106 downregulated genes were identified using the RRA method. The top 50 most significantly upregulated and downregulated genes are clustered in a heatmap (Fig. 1). 


\begin{tabular}{|c|c|c|c|c|}
\hline 4.45 & 3.41 & 4.08 & 127.86 & \multirow{3}{*}{$\begin{array}{l}\text { CHI3L1 } \\
\text { SERPINA1 } \\
\text { SLC34A2 }\end{array}$} \\
\hline 2.99 & 3.49 & 3.01 & 109.26 & \\
\hline 3.61 & 4.14 & 4.12 & 2.43 & \\
\hline 2.08 & 1.90 & 2.06 & 282.72 & CTSH \\
\hline 2.40 & 1.72 & 2.27 & 97.57 & TIMP1 \\
\hline 2.89 & 2.32 & 1.97 & 98.77 & CST6 \\
\hline 3.41 & 4.18 & 4.06 & 10.06 & DCSTAMP \\
\hline 3.89 & 3.68 & 3.24 & 69.47 & CITED1 \\
\hline 3.63 & 3.47 & 3.53 & 5.86 & SFTPB \\
\hline 2.81 & 1.60 & 1.99 & 69.57 & CXCL14 \\
\hline 2.45 & 2.84 & 2.67 & 53.11 & LAMB3 \\
\hline 1.86 & 1.49 & 2.55 & 96.07 & NELL2 \\
\hline 1.58 & 1.43 & 1.69 & 94.22 & IGFBP6 \\
\hline 2.16 & 1.28 & 2.39 & 566.32 & APOE \\
\hline 1.29 & 2.23 & 1.56 & 48.10 & KLK11 \\
\hline 1.86 & 2.03 & 1.72 & 36.69 & LGALS3 \\
\hline 3.06 & 2.58 & 3.57 & 10.36 & LRRK2 \\
\hline 1.60 & 1.74 & 1.77 & 35.22 & GGCT \\
\hline 3.00 & 2.33 & 3.42 & 33.95 & DPP4 \\
\hline 3.35 & 2.77 & 2.88 & 14.38 & ARHGAP36 \\
\hline-3.21 & -4.09 & -4.42 & -420.26 & TFF3 \\
\hline-2.01 & -3.78 & -3.34 & -94.79 & CRABP1 \\
\hline-3.10 & -4.27 & -4.76 & -61.27 & TPO \\
\hline-2.35 & -3.95 & -2.46 & -67.60 & $\mathrm{CDH} 16$ \\
\hline-1.48 & -1.91 & -1.88 & -246.92 & CFD \\
\hline-3.16 & -3.66 & -4.79 & -5.70 & DIO1 \\
\hline-1.40 & -1.75 & -1.83 & -241.46 & HBB \\
\hline-3.09 & -3.52 & -3.97 & -2.25 & MPPED2 \\
\hline-1.57 & -1.67 & -1.75 & -112.19 & HBA2 \\
\hline-2.42 & -3.28 & -3.21 & -5.01 & SLC26A4-AS1 \\
\hline-1.53 & -1.76 & -1.65 & -80.21 & CITED2 \\
\hline-2.20 & -1.40 & -2.08 & -71.14 & FHL1 \\
\hline-1.87 & -2.95 & -2.74 & -45.00 & SLC26A4 \\
\hline-2.49 & -2.95 & -2.80 & -41.76 & HGD \\
\hline-2.34 & -3.06 & -3.48 & -1.40 & GPM6A \\
\hline-1.58 & -1.34 & -1.85 & -114.96 & RGS16 \\
\hline-1.58 & -1.30 & -1.64 & -114.07 & MAFB \\
\hline-1.22 & -1.29 & -2.01 & -195.75 & FCGBP \\
\hline-1.08 & -1.53 & -2.24 & -74.94 & FOSB \\
\hline-1.54 & -2.09 & -2.42 & -37.60 & CCL21 \\
\hline
\end{tabular}

Figure 1. Identification of DEGs in the papillary thyroid carcinoma mRNA expression profiling datasets GSE3678, GSE3467, GSE60542 and GSE97001. The top 50 most significantly upregulated and downregulated DEGs were clustered in a heatmap. Red represents higher expression and green represents lower expression. The values represented are logFC values. DEGs, differentially expressed genes; FC, fold change.

Pathway enrichment analysis using GO and KEGG. GO is considered as the international standard classification system for gene function. A total of 240 DEGs were identified. As shown in Fig. 2A, 'Cellular oxidant detoxification', 'extracellular exosome', 'cell adhesion', 'extracellular matrix', 'collagen binding' and 'protease binding' was enrichment based on GO analysis. KEGG analysis was undertaken using the DAVID tool, which revealed the most significantly enriched pathways included thyroid hormone synthesis, pathways in cancer, focal adhesion, metabolic pathways, apoptosis and the PPAR and PI3K/AKT signaling pathways in KEGG (Fig. 2B).

PPI network analysis. A PPI network of DEGs was first constructed using the STRING database, followed by data visualization by Cytoscape (Fig. 3A). To further mine the significant nodes in the network, topological analysis of each node was performed using the Cytoscape plugin cytoHubba. The 6 most significant genes identified in the PPI network were apolipoprotein E (APOE), hemoglobin subunit $\alpha 1$ (HBA1), angiotensin II receptor type 1 (AGTR1), collagen type I $\alpha 1$ (COL1A1), galectin 3 (LGALS3) and TIMP metallopeptidase inhibitor 1 (TIMP1). The co-expression network of these 6 hub genes based on the TCGA-THCA cohort dataset was constructed using the cBioportal tool (http://www.cbioportal. org/) (Fig. 3B).

Verification of the association of 6 hub genes with prognosis for patients with PTC. A total of 493 patients with PTC and 58 normal thyroid samples were identified in the TCGA-THCA dataset. To validate the reliability of the 6 significant genes identified in the GEO database, the expression level of these genes was assessed in the TCGA database by including 493 
A

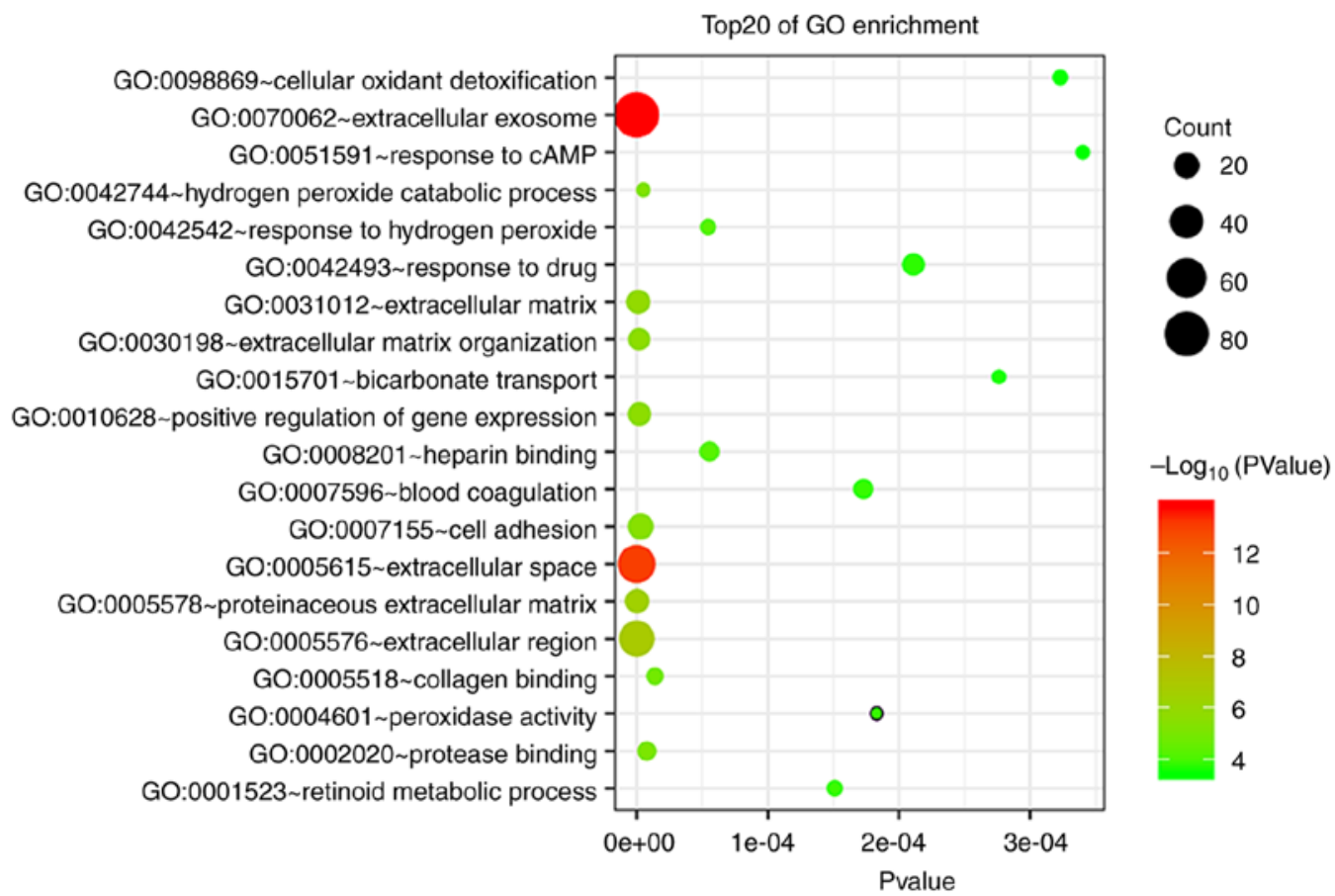

B

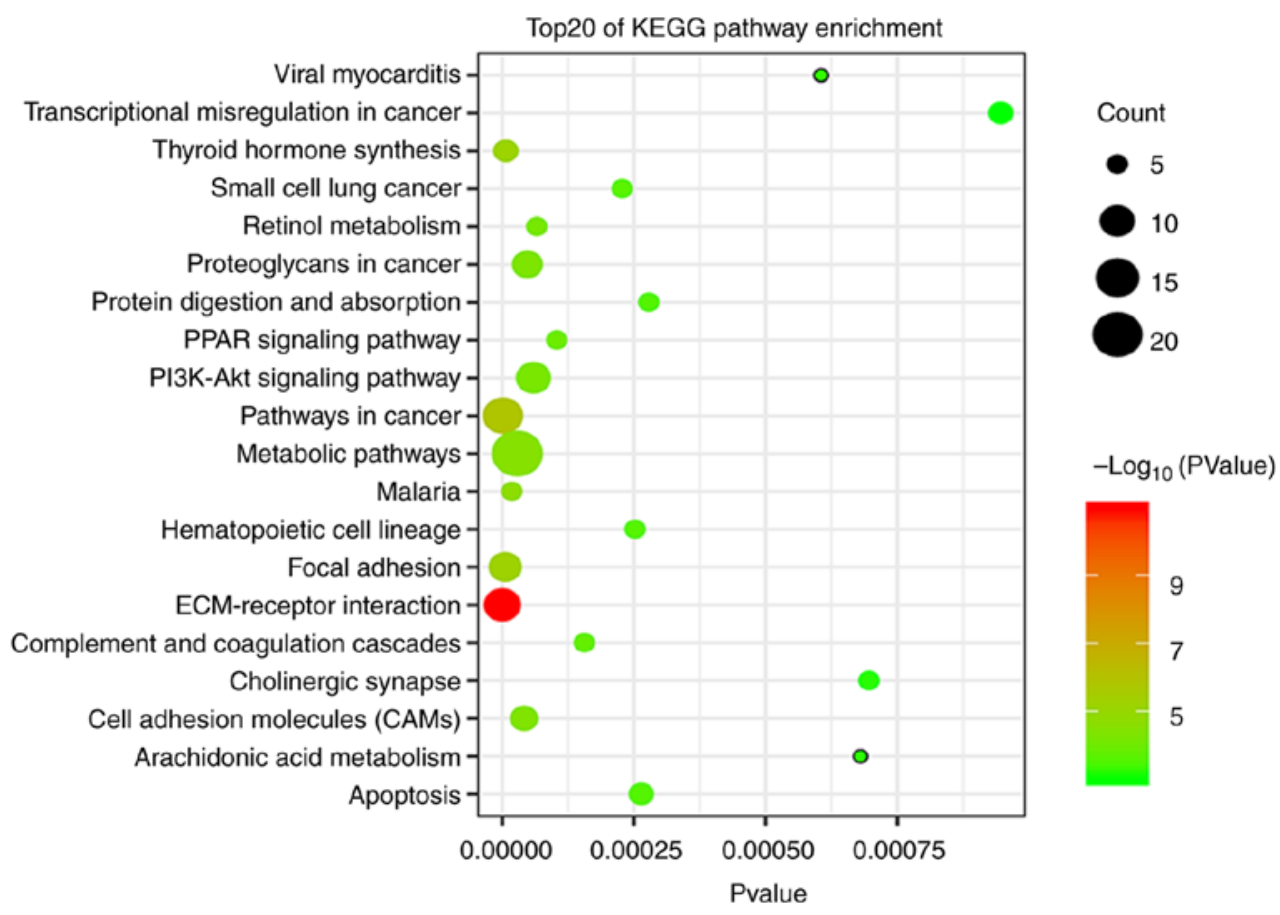

Figure 2. GO terms and KEGG pathways enriched by DEGs. The y-axes correspond to the (A) GO terms or (B) KEGG pathways, and the x-axes show the enrichment factor. The color of the dot represents the P-value, and the size of the dot represents the number of DEGs mapped to the reference GO terms or pathways. DEGs, differentially expressed genes; GO, gene ontology; KEGG, Kyoto Encyclopedia of Genes and Genome.

PTC samples and 58 normal thyroid tissues. As shown in Fig. 4, the expression trends of these genes were in line with previous GEO analysis (Fig. 1). To identify the association between the 6 hub genes and prognosis for patients with PTC, samples from the TCGA database were further categorized into high and low expression groups. As shown in Fig. 5, the expression levels of 4 genes, APOE, COL1A1, LGALS3 and TIMP1, were significantly associated with OS. As shown in Fig. 6, all 6 significant genes were associated with DFS in patients with PTC. Among these genes, APOE had the most significant association with OS ( $\mathrm{P}=0.00067)$ and DFS $(\mathrm{P}=0.00220)$, suggesting that APOE may play a critical role in PTC progression and is significantly associated with prognosis.

Association between APOE expression and clinicopathological features of patients with PTC. To further demonstrate the importance of APOE in PTC and patient prognosis, the association of APOE expression with clinicopathological features of patients with PTC was analyzed using the TCGA dataset. As presented in Table II, low expression of APOE was significantly associated with older age $(\mathrm{P}<0.001)$ and more advanced TNM stage $(\mathrm{P}<0.001)$. The results revealed 


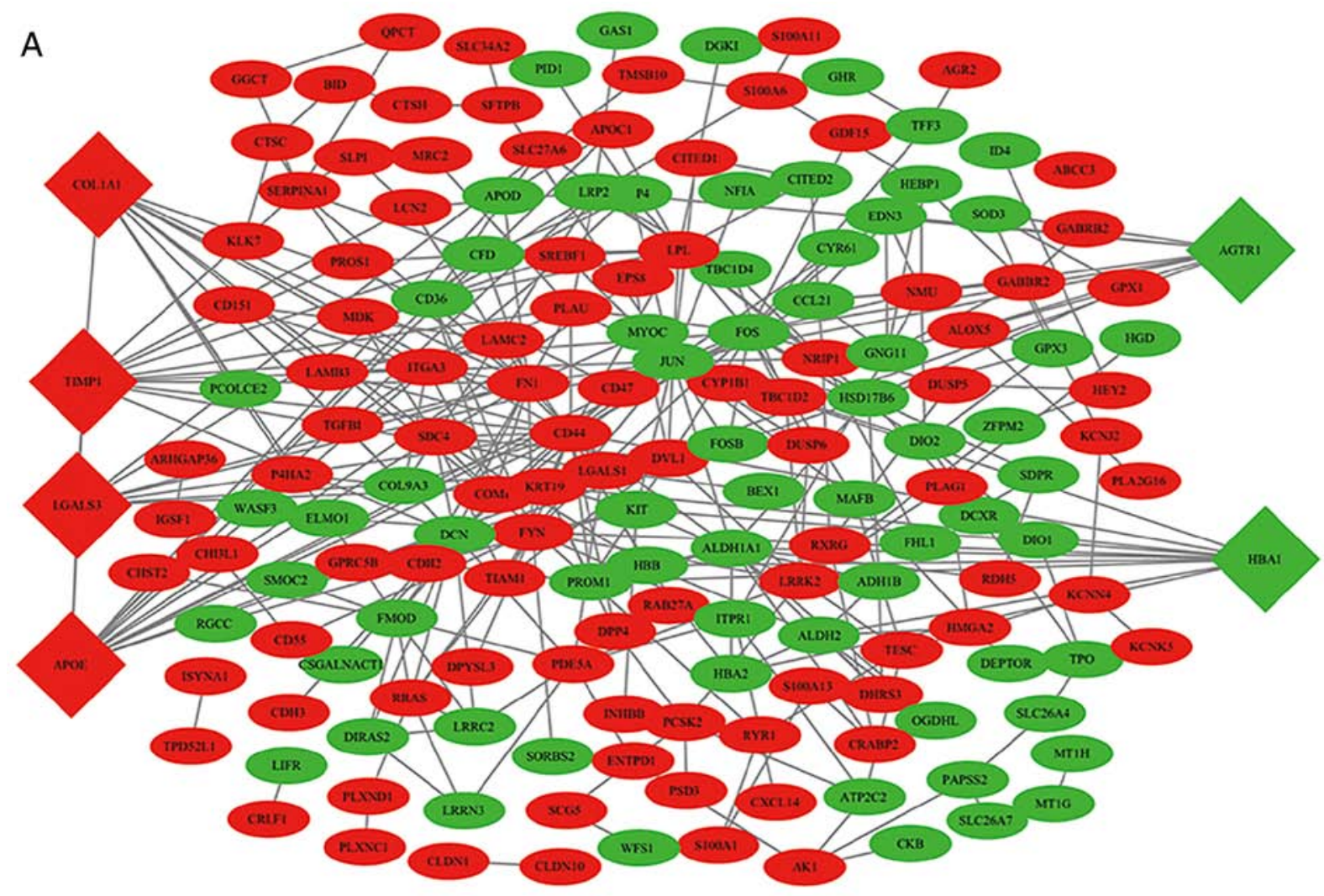

B

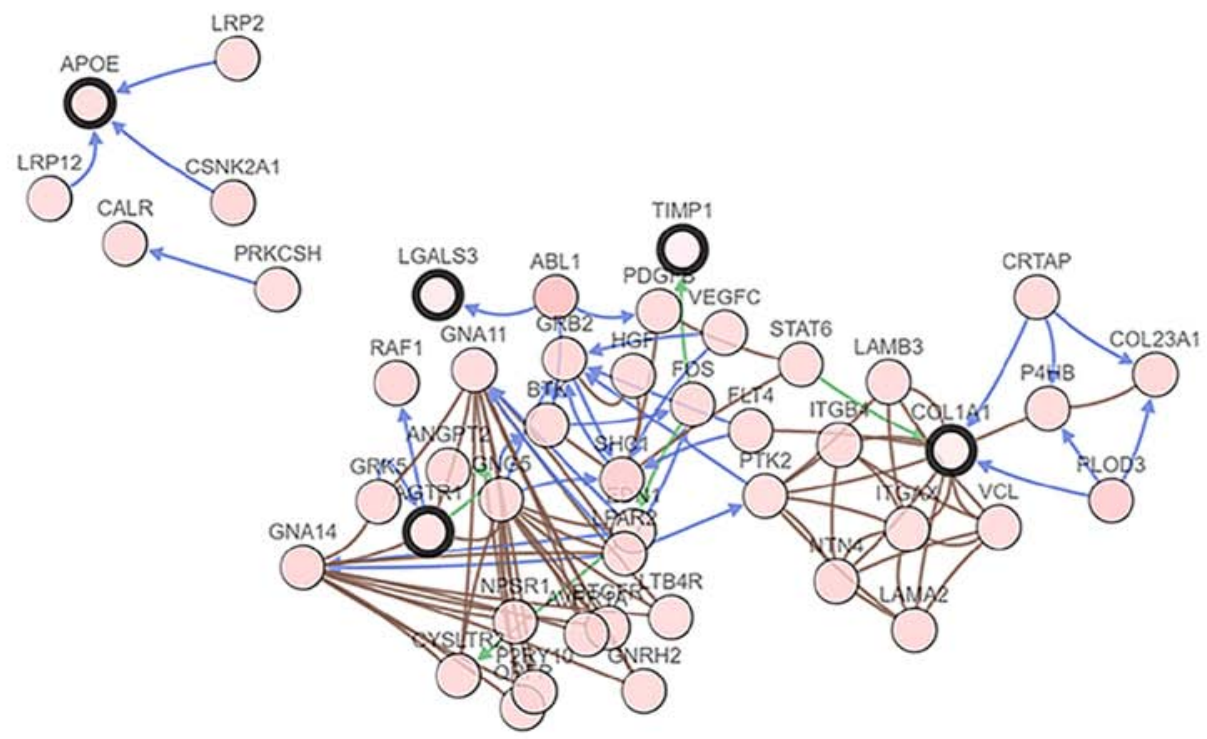

Figure 3. PPI network construction and topological analysis. (A) PPI network of differentially expressed genes. Red stands for upregulated genes, while green stands for downregulated genes. (B) Topological analysis of each node showing the genes in the context of biological interactions derived from public pathway databases. Dots with black borders represent significant genes in the PPI network. The arrows represent direction in signaling pathways. PPI, protein-protein interaction.

that gender, lymph node involvement, distant metastasis and cancer multifocality were not significantly associated with APOE expression. Finally, univariate and multivariate Cox proportional hazard analyses were conducted. As shown in Table III, univariate analysis revealed that the mRNA expression of APOE $(\mathrm{P}=0.002)$ was closely associated with TNM stage $(\mathrm{P}=0.001)$, while multivariate analysis suggested that APOE could be an independent prognostic factor for patients with PTC.

\section{Discussion}

PTC is the most prevalent malignancy in the endocrine system, with a rapid increase in morbidity rate in past two decades (1). Despite the relatively good 5-year survival rate of patients with PTC, tumor recurrence and lymph node metastasis are common, which might impact the OS and DFS of patients with PTC $(30,31)$.

In the present study, DEGs between neoplastic and adjacent tissues of PTC were analyzed using the GEO database. 

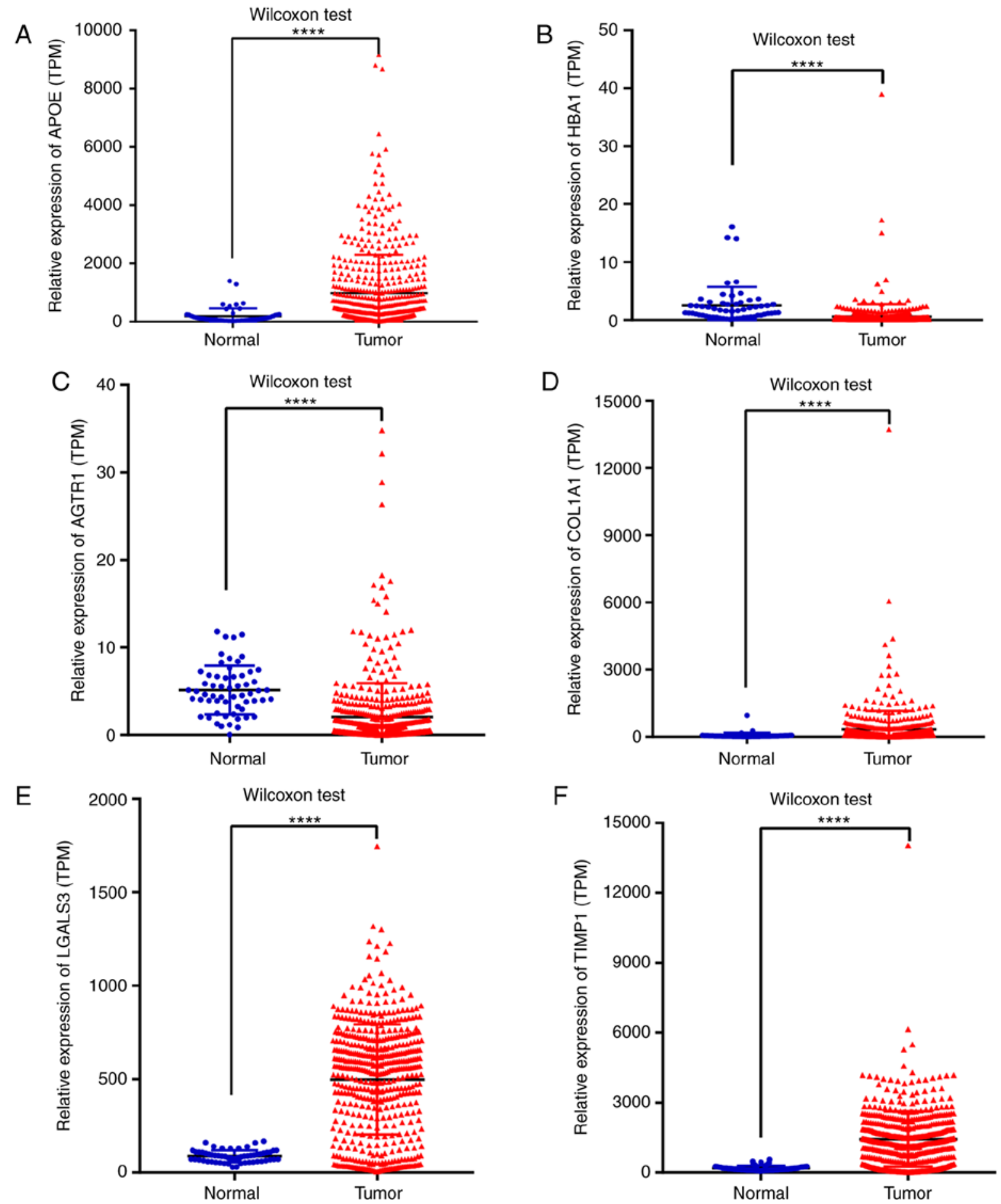

Figure 4. Relative mRNA expression level of hub genes in the TCGA cohort. To compare the expression of (A) APOE, (B) HBA1, (C) AGTR1, (D) COL1A1, (E) LGALS3 and (F) TIMP1 genes in papillary thyroid carcinoma (red) and normal tissues (blue). Statistical differences were analyzed using the Wilcoxon test. ${ }_{* * * *} \mathrm{P}<0.0001$. APOE, apolipoprotein E; HBA1, hemoglobin subunit $\alpha 1$; AGTR1, angiotensin II receptor 1; COL1A1, collagen type I $\alpha 1$; LGALS3, galectin 3; TIMP1, TIMP metallopeptidase inhibitor 1; TPM, transcripts per kilobase million.

Consequently, 134 upregulated and 106 downregulated DEGs were identified. GO and KEGG enrichment analysis, establishment of PPI network and network topological analysis were utilized to identify genes potentially related to the initiation and development of PTC. It can be hypothesized that most of the DEGs identified in the present study were enriched in multiple cancer initiation and development-related pathological processes and signaling pathways based on GO and KEGG enrichment analysis from previous research (32-37). Recent evidence from network biology suggests that genes and proteins do not function in isolation. Instead, they function in interconnected pathways and molecular networks on multiple levels (38). In a previous study the properties and behavior of biological molecules were also identified using the PPI network, suggesting this is an important tool (39). 
A

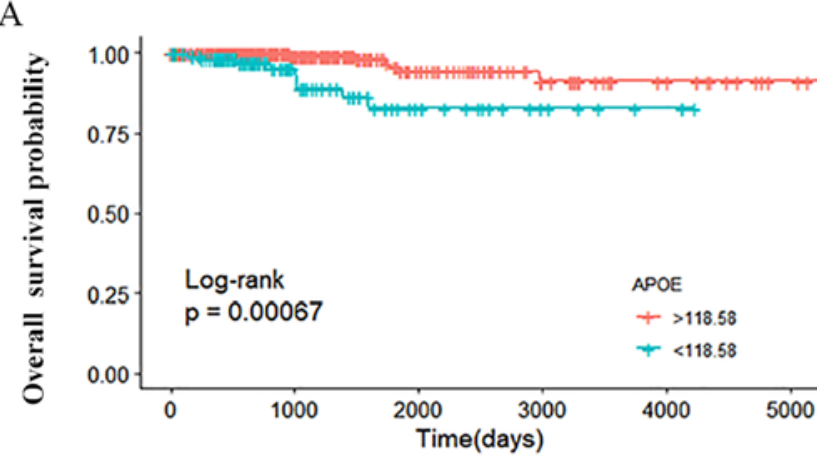

Number at risk

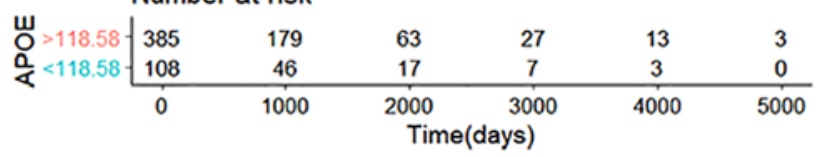

$\mathrm{C}$

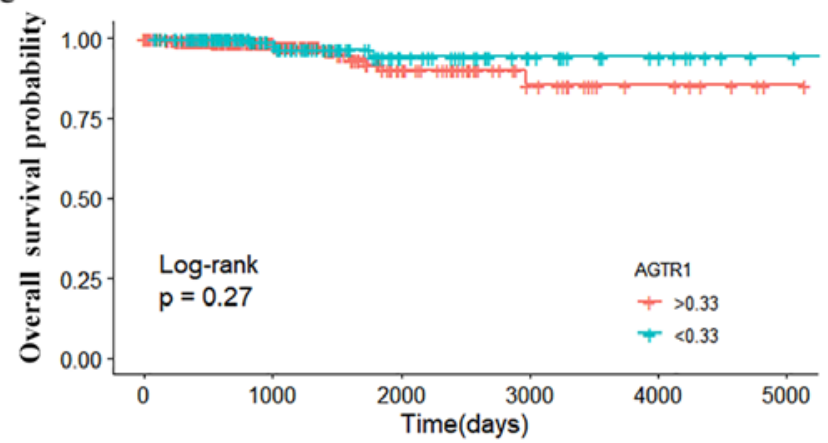

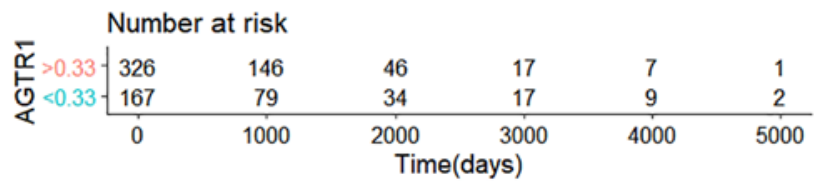

E

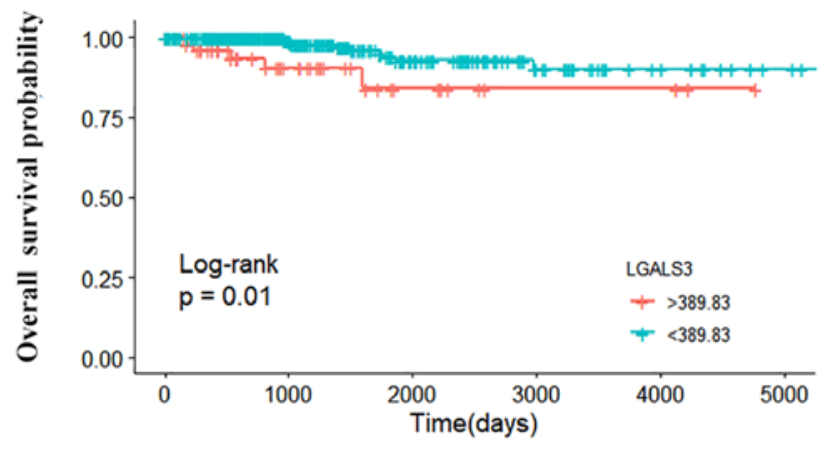

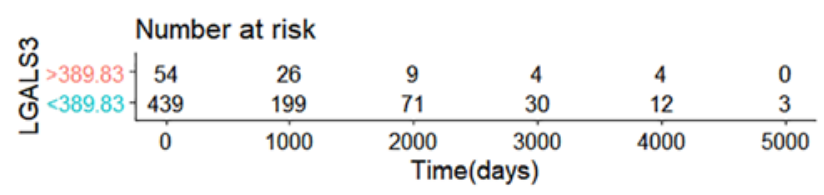

B

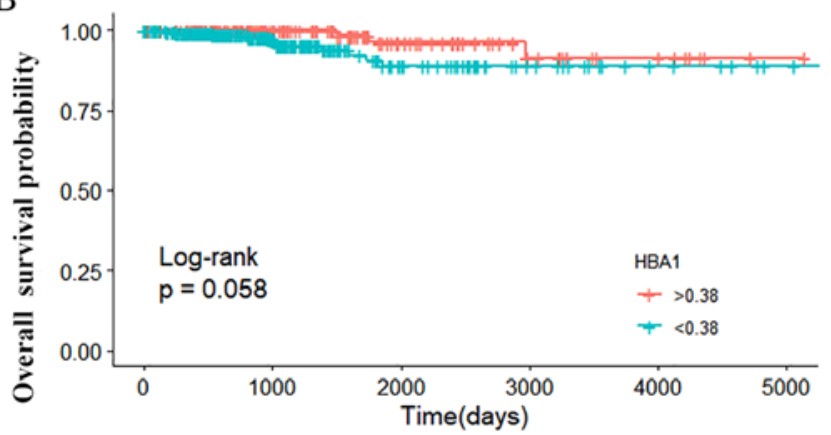

Number at risk

\begin{tabular}{|c|c|c|c|c|c|}
\hline \begin{tabular}{l|l|l}
$\overline{\mathbb{\alpha}}>0.38$ & 175 \\
$\mathbf{\Phi}<0.38$ & 318
\end{tabular} & $\begin{array}{c}88 \\
137\end{array}$ & $\begin{array}{l}38 \\
42\end{array}$ & $\begin{array}{l}17 \\
17\end{array}$ & $\begin{array}{l}9 \\
7\end{array}$ & $\begin{array}{l}1 \\
2\end{array}$ \\
\hline 0 & 1000 & $\begin{array}{r}2000 \\
\mathrm{Tin}\end{array}$ & $\begin{array}{l}3000 \\
\text { vs) }\end{array}$ & 4000 & $50 \mathrm{C}$ \\
\hline
\end{tabular}

$\mathrm{D}$
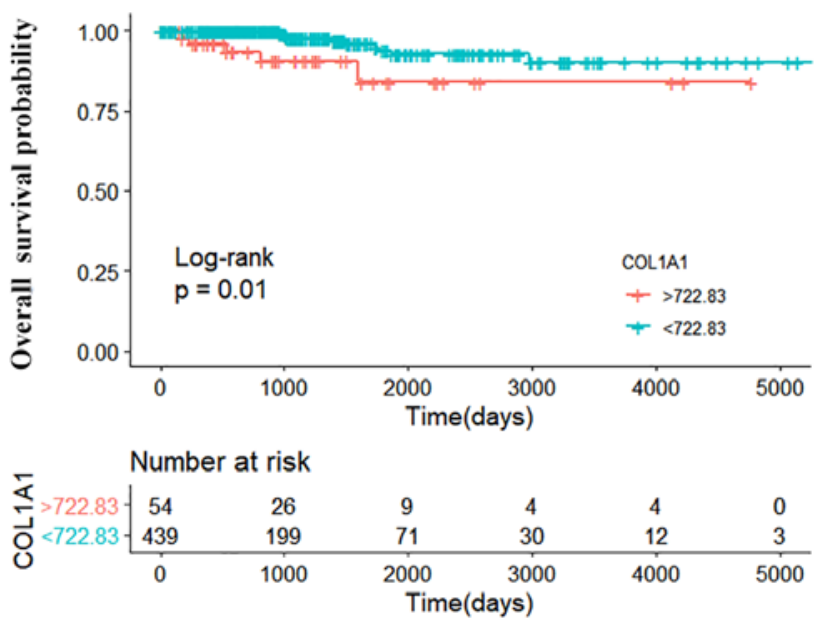

F

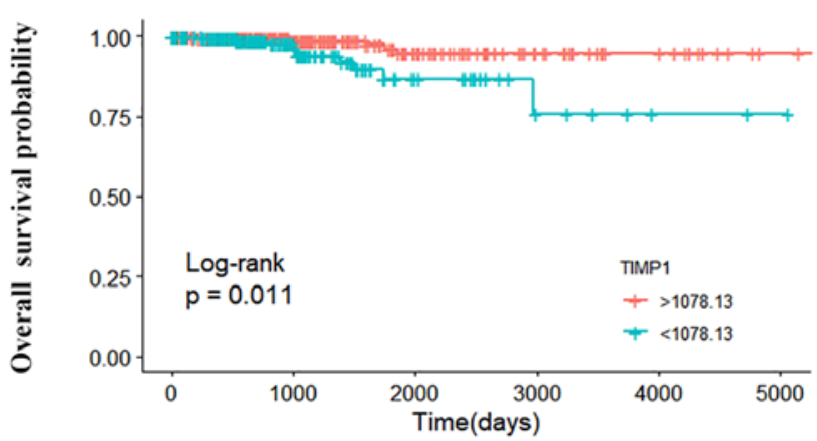

Number at risk

\begin{tabular}{|c|c|c|c|c|c|c|}
\hline$\sum_{\underline{\underline{a}}}^{\bar{\alpha}}>1078.13$. & $\begin{array}{l}299 \\
194\end{array}$ & $\begin{array}{c}146 \\
79\end{array}$ & $\begin{array}{l}59 \\
21\end{array}$ & $\begin{array}{c}28 \\
6\end{array}$ & $\begin{array}{c}14 \\
2\end{array}$ & $\begin{array}{l}2 \\
1\end{array}$ \\
\hline & 0 & 1000 & 2000 & 3000 & 4000 & 5000 \\
\hline
\end{tabular}

Figure 5. Kaplan-Meier survival analysis of the association between hub gene expression level and OS in patients with PTC. Differences in OS in PTC patients with high and low expression of (A) APOE, (B) HBA1, (C) AGTR1, (D) COL1A1, (E) LGALS3 and (F) TIMP1. PTC, papillary thyroid carcinoma; OS, overall survival; APOE, apolipoprotein E; HBA1, hemoglobin subunit $\alpha 1$; AGTR1, angiotensin II receptor 1; COL1A1, collagen type I subunit $\alpha 1$; LGALS3, galectin 3; TIMP1, TIMP metallopeptidase inhibitor 1.

In total, 6 significant hub genes were identified among the DEGs: APOE, HBA1, AGTR1, COL1A1, LGALS3 and TIMP1. Of these 6 genes, HBA1, AGTR1, COL1A1 and TIMP1 have previously been reported to participate in the pathogenesis, development, malignant transformation and pathological process of PTC, and they have been significantly associated with patient survival and prognosis (40-43). These previous studies have confirmed the 
A
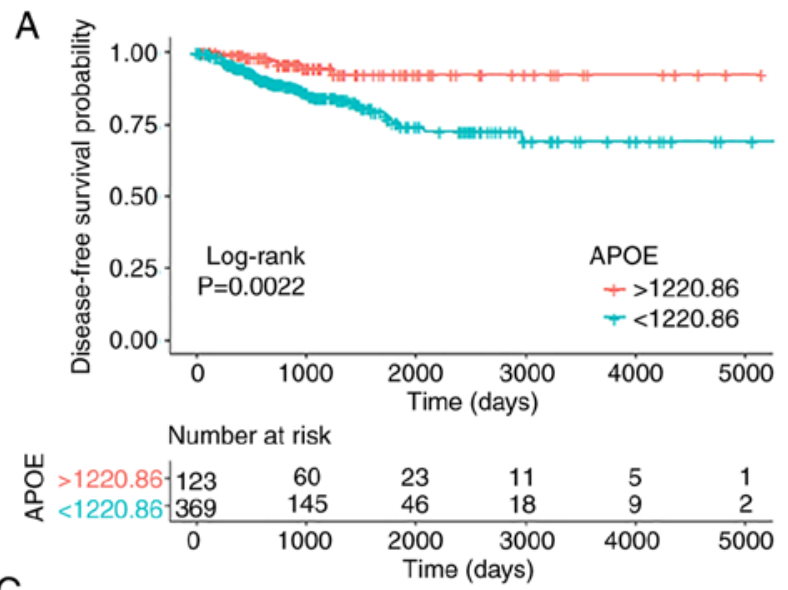

C

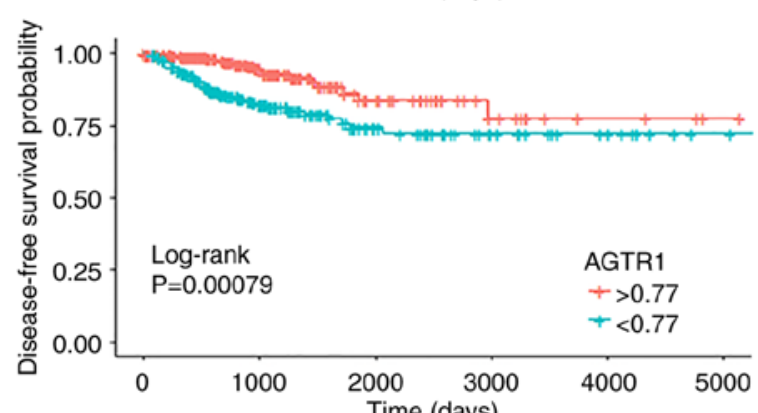

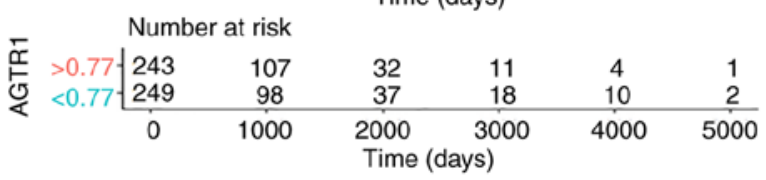

E
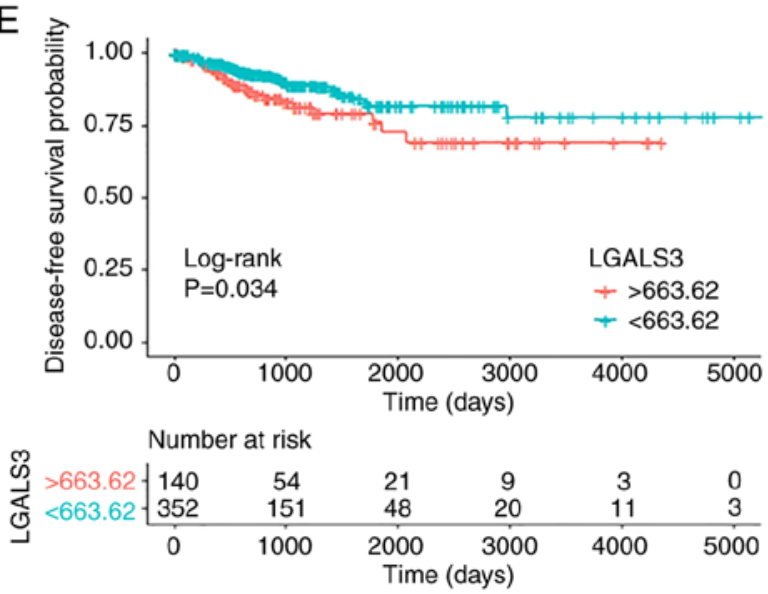

$\mathrm{B}$

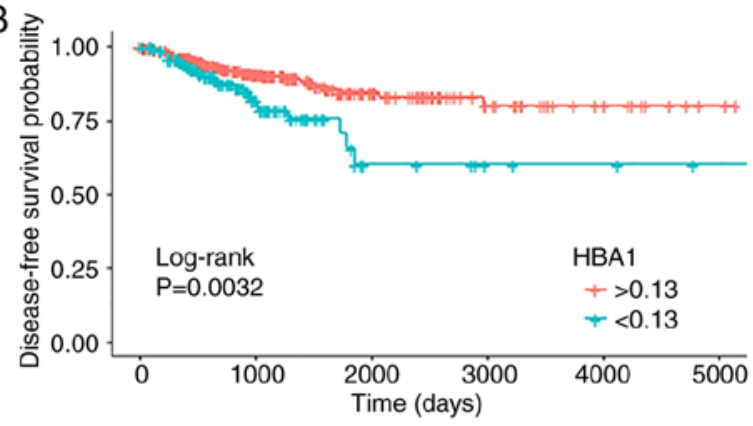

Number at risk
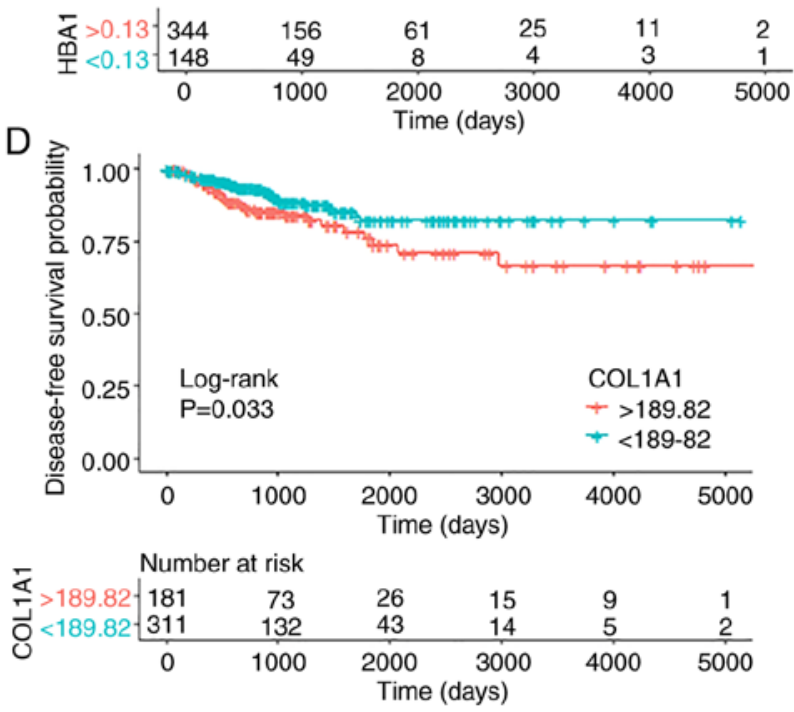

$\mathrm{F}$

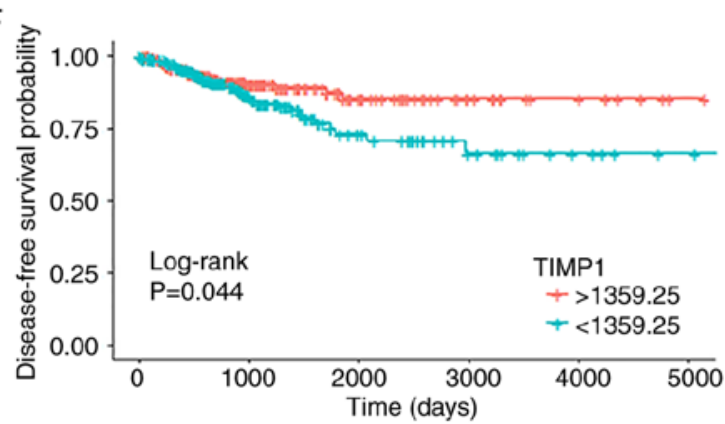

Number at risk

\begin{tabular}{|c|c|c|c|c|c|}
\hline $\begin{array}{l}\overline{\underline{\Sigma}}>1359.25 \\
\underline{\Sigma}><1359.25 \\
2269\end{array}$ & $\begin{array}{l}102 \\
103\end{array}$ & $\begin{array}{l}36 \\
33\end{array}$ & $\begin{array}{l}15 \\
14\end{array}$ & $\begin{array}{l}8 \\
6\end{array}$ & $\begin{array}{l}1 \\
2\end{array}$ \\
\hline 0 & 1000 & $\begin{array}{r}2000 \\
\text { Tim }\end{array}$ & $\begin{array}{l}3000 \\
\text { ays) }\end{array}$ & 4000 & 5000 \\
\hline
\end{tabular}

Figure 6. Kaplan-Meier survival analysis of the association between significant gene expression and DFS in patients with PTC. Differences in DFS in PTC patients with high and low expression of (A) APOE, (B) HBA1, (C) AGTR1, (D) COL1A1, (E) LGALS3 and (F) TIMP1. PTC, papillary thyroid carcinoma; DFS, disease-free survival; APOE, apolipoprotein E; HBA1, hemoglobin subunit $\alpha 1$; AGTR1, angiotensin II receptor 1; COL1A1, collagen type I $\alpha 1$; LGALS3, galectin 3; TIMP1, TIMP metallopeptidase inhibitor 1 .

reliability and accuracy of the bioinformatic mining results in the present study.

APOE is a well-known apolipoprotein that functions in lipoprotein-mediated lipid transport between organs via the plasma and interstitial fluids (44). As a secreted protein, APOE has been implicated in lipoprotein metabolism and the pathogenesis of Alzheimer's disease and atherosclerosis (45-47). However, its association with tumors has rarely been reported. In recent years, an additional role of APOE has been identified in the pathogenesis of tumor metastasis $(48,49)$. APOE can inhibit the invasiveness of melanoma cells and the recruitment of endothelial cells, potentially functioning as a vital barrier to metastatic colonization $(50,51)$. APOE has also been demonstrated to be involved in innate immune modulation, which could be a target to enhance the efficacy of cancer immunotherapy in patients (52). Moreover, the abnormal expression of APOE in lung, colorectal and gastric cancer has been reported (53-56); however, the association between APOE and PTC has not been investigated and should be the basis of future research.

At present, the association of the expression of numerous genes with the survival of patients with PTC is increasingly 
Table II. Association between the expression of APOE and the clinicopathological characteristics of patients with papillary thyroid carcinoma.

APOE expression

\begin{tabular}{|c|c|c|c|}
\hline \multirow[b]{2}{*}{ Variables } & & \multirow[b]{2}{*}{ P-value } \\
\hline & Low, n (\%) & High, n (\%) & \\
\hline Cases & $246(49.89)$ & $247(50.10)$ & \\
\hline Age, years & & & $<0.001$ \\
\hline$<45$ & $88(35.77)$ & $133(53.85)$ & \\
\hline$\geq 45$ & $158(64.23)$ & $114(46.15)$ & \\
\hline Sex & & & 0.663 \\
\hline Male & $179(72.76)$ & $184(74.49)$ & \\
\hline Female & $67(27.24)$ & $63(25.51)$ & \\
\hline T stage & & & $<0.001$ \\
\hline $\mathrm{T} 1+\mathrm{T} 2$ & $134(54.47)$ & $171(69.80)$ & \\
\hline $\mathrm{T} 3+\mathrm{T} 4$ & $112(45.53)$ & $74(30.20)$ & \\
\hline Lymph node metastasis & & & 0.728 \\
\hline N0 & $111(51.87)$ & $115(50.22)$ & \\
\hline N1 & $103(48.13)$ & $114(40.78)$ & \\
\hline Distant metastasis & & & 0.833 \\
\hline M0 & $133(97.08)$ & $144(96.64)$ & \\
\hline M1 & $4(2.92)$ & $5(3.36)$ & \\
\hline TNM stage & & & $<0.001$ \\
\hline $\mathrm{I}+\mathrm{II}$ & $144(58.78)$ & $182(61.79)$ & \\
\hline III+IV & $101(41.22)$ & $64(38.21)$ & \\
\hline Multifocality & & & 0.491 \\
\hline Unifocal & $135(56.02)$ & $128(52.89)$ & \\
\hline Multifocal & $106(43.98)$ & $114(47.11)$ & \\
\hline
\end{tabular}

APOE, apolipoprotein E; TNM, tumor node metastasis.

Table III. Univariate and multivariate Cox regression analyses of APOE.

\begin{tabular}{|c|c|c|c|c|c|c|}
\hline \multirow[b]{2}{*}{ Variables } & \multicolumn{3}{|c|}{ Univariate } & \multicolumn{3}{|c|}{ Multivariate } \\
\hline & HR & $95 \% \mathrm{CI}$ & P-value & HR & $95 \% \mathrm{CI}$ & P-value \\
\hline Age, $<45$ vs. $\geq 45$ years & 1.417 & $0.786-2.554$ & 0.246 & & & \\
\hline Gender, female vs. male & 2.038 & $0.737-5.643$ & 0.170 & & & \\
\hline TNM stage, I+II vs. III+IV & 7.142 & $2.298-22.194$ & 0.001 & 6.211 & $1.542-25.007$ & 0.010 \\
\hline $\mathrm{T}, \mathrm{T} 1+\mathrm{T} 2$ vs. T3+T4 & 3.052 & $1.058-8.805$ & 0.039 & 0.866 & $0.227-3.229$ & 0.833 \\
\hline N, N0 vs. N1 & 1.455 & $0.475-4.459$ & 0.512 & & & \\
\hline M, M0 vs. M1 & 4.179 & $0.892-19.571$ & 0.070 & & & \\
\hline Multifocality, unifocal vs. multifocal & 0.431 & $0.213-0.872$ & 0.770 & & & \\
\hline APOE expression high vs. low & 0.211 & $0.079-0.568$ & 0.002 & 0.286 & $0.102-0.797$ & 0.017 \\
\hline
\end{tabular}

HR, hazard ratio; CI, confidence interval; APOE, apolipoprotein E; TNM, tumor node metastasis.

being mined. The majority of present studies are validated in animal tumor models, in vitro cell models or small-scale clinical studies $(57,58)$. However, large-scale studies with more comprehensive analysis and larger cohorts are required due to the complexity of PTC. Fortunately, the rapid development of genome-wide sequencing has led to the development of publicly-available high-throughput tumor databases such as GEO and TCGA, which have made it possible to conduct bioinformatic analysis of large datasets of patients with PTC. 


\section{Acknowledgements}

Not applicable.

\section{Funding}

The present study was supported by the Youth Fund of the Second Affiliated Hospital to Nanchang University (grant no. 2016YNQN12026) and the Young and Middle-aged Doctor Research Project of the Thyroid Gland from China Health Promotion Foundation and the Natural Science Foundation in China (grant nos. 81660294,.81560397 and 81660403, respectively).

\section{Availability of data and materials}

The datasets generated and/or analyzed during the present study are available in the Gene Expression Omnibus repository (https://www.ncbi.nlm.nih.gov/geo/) and The Cancer Genome Atlas repository (https://portal.gdc.cancer.gov/).

\section{Authors' contributions}

YXL and QGJ designed the study. QGJ and WQF collected and analyzed the data. YXL drafted, wrote and critically revised the manuscript. CFX analyzed the data. YXL critically revised the manuscript. All authors had intellectual input into the study and approved the final version of the manuscript.

\section{Ethics approval and consent to participate}

Not applicable.

\section{Patient consent for publication}

Not applicable.

\section{Competing interests}

The authors declare that they have no competing interests.

\section{References}

1. Bray F, Ferlay J, Soerjomataram I, Siegel RL, Torre LA and Jemal A: Global cancer statistics 2018: GLOBOCAN estimates of incidence and mortality worldwide for 36 cancers in 185 countries. CA Cancer J Clin 68: 394-424, 2018.

2. Xing $M$, Haugen BR and Schlumberger $M$ : Progress in molecular-based management of differentiated thyroid cancer. Lancet 381: 1058-1069, 2013.

3. Rusinek D, Pfeifer A, Krajewska J, Oczko-Wojciechowska M, Handkiewicz-Junak D, Pawlaczek A, Zebracka-Gala J, Kowalska M, Cyplinska R, Zembala-Nozynska E, et al: Coexistence of TERT promoter mutations and the BRAF V600E alteration and its impact on histopathological features of papillary thyroid carcinoma in a selected series of polish patients Int J Mol Sci 19: E2647, 2018.

4. Kwak HY, Chae BJ, Eom YH, Hong YR, Seo JB, Lee SH, Song BJ, Jung SS and Bae JS: Does papillary thyroid carcinoma have a better prognosis with or without Hashimoto thyroiditis? Int J Clin Oncol 20: 463-473, 2015.

5. Selmansberger M, Feuchtinger A, Zurnadzhy L, Michna A, Kaiser JC, Abend M, Brenner A, Bogdanova T, Walch A, Unger K, et al: CLIP2 as radiation biomarker in papillary thyroid carcinoma. Oncogene 34: 3917-3925, 2015.
6. Liu Z, Cai J, Yu Y, Fang H, Si Y, Jankee JJ and Shen M: Tumor abnormal protein as a novel biomarker in papillary thyroid carcinoma. Clin Lab 63: 479-485, 2017.

7. Giordano TJ, Kuick R, Thomas DG, Misek DE, Vinco M, Sanders D, Zhu Z, Ciampi R, Roh M, Shedden K, et al: Molecular classification of papillary thyroid carcinoma: Distinct BRAF, RAS, and RET/PTC mutation-specific gene expression profiles discovered by DNA microarray analysis. Oncogene 24: 6646-6656, 2005.

8. Ciampi R, Knauf JA, Kerler R, Gandhi M, Zhu Z, Nikiforova MN, Rabes HM, Fagin JA and Nikiforov YE: Oncogenic AKAP9-BRAF fusion is a novel mechanism of MAPK pathway activation in thyroid cancer. J Clin Invest 115: 94-101, 2005.

9. Crescenzi A, Guidobaldi L, Nasrollah N, Taccogna S, Cicciarella Modica DD, Turrini L, Nigri G, Romanelli F, Valabrega S, Giovanella L, et al: Immunohistochemistry for BRAF(V600E) antibody VE1 performed in core needle biopsy samples identifies mutated papillary thyroid cancers. Horm Metab Res 46: 370-374, 2014.

10. Clinkscales W, Ong A, Nguyen S, Harruff EE and Gillespie MB: Diagnostic value of RAS mutations in indeterminate thyroid nodules. Otolaryngol Head Neck Surg 156: 472-479, 2017.

11. Fagin JA and Wells SA Jr: Biologic and clinical perspectives on thyroid cancer. N Engl J Med 375: 2307, 2016.

12. Lima CR, Geraldo MV, Fuziwara CS, Kimura ET and Santos MF: MiRNA-146b-5p upregulates migration and invasion of different Papillary Thyroid Carcinoma cells. BMC Cancer 16: 108, 2016.

13. Condello V, Torregrossa L, Sartori C, Denaro M, Poma AM, Piaggi P, Valerio L, Materazzi G, Elisei R, Vitti P and Basolo F: mRNA and miRNA expression profiling of follicular variant of papillary thyroid carcinoma with and without distant metastases. Mol Cell Endocrinol 479: 93-102, 2019.

14. Chen F, Yin S, Zhu J, Liu P, Yang C, Feng Z and Deng Z: lncRNA DGCR5 acts as a tumor suppressor in papillary thyroid carcinoma via sequestering miR-2861. Exp Ther Med 17: 895-900, 2019.

15. Matsumoto Y, Saito M, Saito K, Kanke Y, Watanabe Y, Onozawa H, Hayase S, Sakamoto W, Ishigame T, Momma T, et al: Enhanced expression of KIF4A in colorectal cancer is associated with lymph node metastasis. Oncol Lett 15: 2188-2194, 2018.

16. Liu C, Song YH, Mao Y, Wang HB and Nie G: MiRNA-106a promotes breast cancer progression by regulating DAX-1. Eur Rev Med Pharmacol Sci 23: 1574-1583, 2019.

17. Lundgren S, Fagerstrom-Vahman H, Zhang C, Ben-Dror L, Mardinoglu A, Uhlen M, Nodin B and Jirström K: Discovery of KIRREL as a biomarker for prognostic stratification of patients with thin melanoma. Biomark Res 7: 1, 2019.

18. Edgar R, Domrachev M and Lash AE: Gene Expression Omnibus: NCBI gene expression and hybridization array data repository. Nucleic Acids Res 30: 207-210, 2002.

19. He H, Jazdzewski K, Li W, Liyanarachchi S, Nagy R, Volinia S, Calin GA, Liu CG, Franssila K, Suster S, et al: The role of microRNA genes in papillary thyroid carcinoma. Proc Natl Acad Sci USA 102: 19075-19080, 2005.

20. Tarabichi M, Saiselet M, Tresallet C, Hoang C, Larsimont D, Andry G, Maenhaut C and Detours V: Revisiting the transcriptional analysis of primary tumours and associated nodal metastases with enhanced biological and statistical controls: Application to thyroid cancer. Br J Cancer 112: 1665-1674, 2015.

21. Iacobas DA, Tuli NY, Iacobas S, Rasamny JK, Moscatello A, Geliebter J and Tiwari RK: Gene master regulators of papillary and anaplastic thyroid cancers. Oncotarget 9: 2410-2424, 2017.

22. Diboun I, Wernisch L, Orengo CA and Koltzenburg M: Microarray analysis after RNA amplification can detect pronounced differences in gene expression using limma. BMC Genomics 7: 252, 2006.

23. Dennis G Jr, Sherman BT, Hosack DA, Yang J, Gao W, Lane HC and Lempicki RA: DAVID: Database for annotation, visualization, and integrated discovery. Genome Biol 4: P3, 2003.

24. Ashburner M, Ball CA, Blake JA, Botstein D, Butler H, Cherry JM, Davis AP, Dolinski K, Dwight SS, Eppig JT, et al: Gene ontology: Tool for the unification of biology. The gene ontology consortium. Nat Genet 25: 25-29, 2000.

25. Kanehisa M, Furumichi M, Tanabe M, Sato Y and Morishima K: KEGG: New perspectives on genomes, pathways, diseases and drugs. Nucleic Acids Res 45: D353-D361, 2017.

26. Szklarczyk D, Morris JH, Cook H, Kuhn M, Wyder S, Simonovic M, Santos A, Doncheva NT, Roth A, Bork P, et al: The STRING database in 2017: Quality-controlled protein-protein association networks, made broadly accessible. Nucleic Acids Res 45: D362-D368, 2017. 
27. Chin $\mathrm{CH}$, Chen $\mathrm{SH}$, Wu HH, Ho CW, Ko MT and Lin CY: cytoHubba: Identifying hub objects and sub-networks from complex interactome. BMC Syst Biol 8 (Suppl 4): S11, 2014.

28. Tan J, Qian X, Song B, An X, Cai T, Zuo Z, Ding D, Lu Y and Li H: Integrated bioinformatics analysis reveals that the expression of cathepsin $\mathrm{S}$ is associated with lymph node metastasis and poor prognosis in papillary thyroid cancer. Oncol Rep 40: 111-122, 2018.

29. Asa SL, Giordano TJ and LiVolsi VA: Implications of the TCGA genomic characterization of papillary thyroid carcinoma for thyroid pathology: Does follicular variant papillary thyroid carcinoma exist? Thyroid 25: 1-2, 2015

30. Wang K, Xu J, Li S, Liu S and Zhang L: Population-based study evaluating and predicting the probability of death resulting from thyroid cancer among patients with papillary thyroid microcarcinoma. Cancer Med 8: 6977-6985, 2019.

31. Londero SC, Krogdahl A, Bastholt L, Overgaard J, Pedersen HB Hahn CH, Bentzen J, Schytte S, Christiansen P, Gerke O, et al: Papillary thyroid carcinoma in Denmark, 1996-2008: Outcome and evaluation of established prognostic scoring systems in a prospective national cohort. Thyroid 25: 78-84, 2015 .

32. Rappa G, Puglisi C, Santos MF, Forte S, Memeo L and Lorico A: Extracellular vesicles from thyroid carcinoma: The New Frontier of Liquid Biopsy. Int J Mol Sci 20: E1114, 2019.

33. Andriescu EC, Caruntu ID, Giusca SE, Lozneanu L and Ciobanu Apostol DG: Prognostic significance of cell-adhesion molecules in histological variants of papillary thyroid carcinoma. Rom J Morphol Embryol 59: 721-727, 2018

34. Tang T and Zhang DL: Study on extracellular matrix metalloproteinase inducer and human epidermal growth factor receptor-2 protein expression in papillary thyroid carcinoma using a quantum dot-based immunofluorescence technique. Exp Ther Med 9: 1331-1335, 2015

35. Selemetjev S, Bartolome A, Isic Dencic T, Đorić I, Paunović I, Tatić S and Cvejić D: Overexpression of epidermal growth factor receptor and its downstream effector, focal adhesion kinase, correlates with papillary thyroid carcinoma progression. Int J Exp Pathol 99: 87-94, 2018.

36. Arts RJ, Plantinga TS, Tuit S, Ulas T, Heinhuis B, Tesselaar M, Sloot Y, Adema GJ, Joosten LA, Smit JW, et al: Transcriptional and metabolic reprogramming induce an inflammatory phenotype in non-medullary thyroid carcinoma-induced macrophages Oncoimmunology 5: e1229725, 2016.

37. French CA, Fletcher JA, Cibas ES, Caulfield C, Allard P and Kroll TG: Molecular detection of PPAR gamma rearrangements and thyroid carcinoma in preoperative fine-needle aspiration biopsies. Endocr Pathol 19: 166-174, 2008.

38. Miryala SK, Anbarasu A and Ramaiah S: Discerning molecular interactions: A comprehensive review on biomolecular interaction databases and network analysis tools. Gene 642: 84-94, 2018.

39. Wang S, Wang H and Lu Y: Tianfoshen oral liquid: A CFDA approved clinical traditional Chinese medicine, normalizes major cellular pathways disordered during colorectal carcinogenesis. Oncotarget 8: 14549-14569, 2017.

40. Wasenius VM, Hemmer S, Kettunen E, Knuutila S, Franssila K and Joensuu H: Hepatocyte growth factor receptor, matrix metalloproteinase-11, tissue inhibitor of metalloproteinase-1, and fibronectin are up-regulated in papillary thyroid carcinoma: A cDNA and tissue microarray study. Clin Cancer Res 9: 68-75, 2003.

41. Qiu J, Zhang W, Xia Q, Liu F, Li L, Zhao S, Gao X, Zang C, Ge R and Sun Y: RNA sequencing identifies crucial genes in papillary thyroid carcinoma (PTC) progression. Exp Mol Pathol 100: 151-159, 2016.

42. Hawthorn L, Stein L, Varma R, Wiseman S, Loree T and Tan D TIMP1 and SERPIN-A overexpression and TFF3 and CRABP1 underexpression as biomarkers for papillary thyroid carcinoma. Head Neck 26: 1069-1083, 2004.
43. Lin P, Guo YN, Shi L, Li XJ, Yang H, He Y, Li Q, Dang YW, Wei KL and Chen G: Development of a prognostic index based on an immunogenomic landscape analysis of papillary thyroid cancer. Aging (Albany NY) 11: 480-500, 2019.

44. Verghese PB, Castellano JM, Garai K, Wang Y, Jiang H, Shah A, $\mathrm{Bu}$ G, Frieden $\mathrm{C}$ and Holtzman DM: ApoE influences amyloid- $\beta$ $(\mathrm{A} \beta)$ clearance despite minimal apoE/A $\beta$ association in physiological conditions. Proc Natl Acad Sci USA 110: E1807-E1816, 2013.

45. Zokaei N, Cepukaityte G, Board AG, Mackay CE, Husain M and Nobre AC: Dissociable effects of the apolipoprotein-E (APOE) gene on short- and long-term memories. Neurobiol Aging 73 115-122, 2019.

46. Zheng L, Duan J, Duan X, Zhou W, Chen C, Li Y, Chen J, Zhou W, Wang YJ, Li T and Song W: Association of Apolipoprotein E (ApoE) polymorphism with Alzheimer's disease in Chinese population. Curr Alzheimer Res 13: 912-917, 2016.

47. Weber $\mathrm{C}$ and Soehnlein O: ApoE controls the interface linking lipids and inflammation in atherosclerosis. J Clin Invest 121: 3825-3827, 2011

48. An HJ, Koh HM and Song DH: Apolipoprotein E is a predictive marker for assessing non-small cell lung cancer patients with lymph node metastasis. Pathol Res Pract 215: 152607, 2019.

49. Zhao Z, Zou S, Guan X, Wang M, Jiang Z, Liu Z, Li C, Lin H, Liu X, Yang R, et al: Apolipoprotein E overexpression is associated with tumor progression and poor survival in colorectal cancer. Front Genet 9: 650, 2018.

50. LXR agonism inhibits metastatic melanoma through activation of ApoE. Cancer Discov 4: OF16, 2014

51. Pencheva N, Tran H, Buss C, Huh D, Drobnjak M, Busam K and Tavazoie SF: Convergent multi-miRNA targeting of ApoE drives LRP1/LRP8-dependent melanoma metastasis and angiogenesis. Cell 151: 1068-1082, 2012.

52. Tavazoie MF, Pollack I, Tanqueco R, Ostendorf BN, Reis BS, Gonsalves FC, Kurth I, Andreu-Agullo C, Derbyshire ML, Posada $\mathrm{J}$, et al: LXR/ApoE activation restricts innate immune suppression in cancer. Cell 172: 825-840.e18, 2018.

53. Tahmasbpour E, Ghanei $M$ and Panahi Y: Two lung cancer development-related genes, Forkhead Box M1 (FOXM1) and Apolipoprotein E (APOE), are overexpressed in Bronchial of patients after long-term exposure to Sulfur Mustard. Iran J Pharm Res 16: 1487-1494, 2017.

54. Liu Z, Gao Y, Hao F, Lou X, Zhang X, Li Y, Wu D, Xiao T, Yang L, Li Q, et al: Secretomes are a potential source of molecular targets for cancer therapies and indicate that APOE is a candidate biomarker for lung adenocarcinoma metastasis. Mol Biol Rep 41: 7507-7523, 2014.

55. Sakashita K, Tanaka F, Zhang X, Mimori K, Kamohara Y, Inoue $\mathrm{H}$, Sawada T, Hirakawa K and Mori M: Clinical significance of ApoE expression in human gastric cancer. Oncol Rep 20: 1313-1319, 2008.

56. Slattery ML, Sweeney C, Murtaugh M, Ma KN, Potter JD, Levin TR, Samowitz W and Wolff R: Associations between apoE genotype and colon and rectal cancer. Carcinogenesis 26: 1422-1429, 2005.

57. Liu F, Zhang J, Qin L, Yang Z, Xiong J, Zhang Y, Li R, Li S, Wang H, Yu B, et al: Circular RNA EIF6 (Hsa_circ_0060060) sponges miR-144-3p to promote the cisplatin-resistance of human thyroid carcinoma cells by autophagy regulation. Aging (Albany NY) 10: 3806-3820, 2018

58. Jia M, Shi Y, Li Z, Lu X and Wang J: MicroRNA-146b-5p as an oncomiR promotes papillary thyroid carcinoma development by targeting CCDC6. Cancer Lett 443: 145-156, 2019.

This work is licensed under a Creative Commons Attribution-NonCommercial-NoDerivatives 4.0 International (CC BY-NC-ND 4.0) License. 